\title{
Comparison of short-term results of open and laparoscopic surgery in gastric cancer at a new regional hospital: a single surgeon experience
}

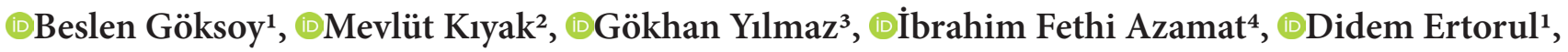 \\ ๑Ömer Faruk İnanç ${ }^{1}$, @Çiğdem Dicle Arıcan ${ }^{5}$, ๑İbrahim Çil ${ }^{6}, \oplus$ Mehmet Altan Bitirim ${ }^{1}$ \\ ${ }^{1}$ Şehit Prof. Dr. İlhan Varank Training and Research Hospital, Department of General Surgery, İstanbul, Turkey \\ ${ }^{2}$ Şehit Prof. Dr. İlhan Varank Training and Research Hospital, Department of Gastroenterology, İstanbul, Turkey \\ ${ }^{3}$ İstanbul Medipol University, Department of General Surgery, İstanbul, Turkey \\ ${ }^{4}$ Koç University Hospital, Department of General Surgery, İstanbul, Turkey \\ ${ }^{5}$ Şehit Prof. Dr. İlhan Varank Training and Research Hospital, Department of Pathology, İstanbul, Turkey \\ ${ }^{6}$ Umraniye Training and Research Hospital, Department of Oncology, İstanbul, Turkey
}

Cite this article as: Göksoy B, Kiyak M, Yllmaz G, et al. Comparison of short-term results of open and laparoscopic surgery in gastric cancer at a new regional hospital: a single surgeon experience. J Health Sci Med 2021; 4(5): 569-575.

\begin{abstract}
Aim: To compare the short-term results of open and laparoscopic gastrectomy in gastric cancer surgery.

Material and Method: From 15 May 2018 to 28 June 2021, patients who underwent open and laparoscopic gastrectomy for gastric cancer by a single surgeon between were retrospectively analyzed from a prospectively maintained database. Patients were compared in terms of early intraoperative and postoperative outcomes. Both surgical methods were compared in terms of early intraoperative and postoperative outcomes.

Results: A total of 34 patients (open $n=23$, laparoscopic $n=11$ ) were included in the study. While the mean number of lymph nodes was similar between the groups, more metastatic lymph nodes and more advanced disease were detected in the open group ( $\mathrm{p}=0.007, \mathrm{p}=0.002$, respectively). According to tumor location, patients who underwent laparoscopic gastrectomy were more distally located $(\mathrm{p}=0.01)$. The mean operative time was shorter in the open group $(171.5 \mathrm{~min}$ and $206 \mathrm{~min}, \mathrm{p}=0.006$, respectively), while the estimated blood loss was less in the laparoscopic group ( $158.2 \mathrm{~mL}$ vs $186.7 \mathrm{~mL}, \mathrm{p}=0.003)$. Four patients (17.4\%) in the open group and two patients (18\%) in the laparoscopic group had at least Clavien-Dindo grade III complications $(\mathrm{p}=0.96)$. Earlier gas output was seen in the laparoscopic group $(\mathrm{p}=0.002)$, while other postoperative outcomes were similar between the groups. Mean follow-up time was longer in the open group (13.4 months and 7.6 months, respectively, $\mathrm{p}=0.004)$.

Conclusion: Until sufficient experience is reached in laparoscopic gastrectomy, choosing earlier stage and distally located tumors is a safe method with postoperative results similar to open gastrectomy.
\end{abstract}

Keywords: Gastric cancer, open gastrectomy, laparoscopic gastrectomy, experience

\section{INTRODUCTION}

According to GLOBACAN 2020 data, gastric cancer is the fifth most common cancer type with a rate of $5,6 \%$ and the third most common cause of cancer-related deaths (7.7\%) worldwide. Although its incidence is similar in Turkey, it ranks second after lung cancer (8.5\%) in cancer-related deaths (1). The curative treatment of gastric cancer without distant metastasis is surgery. In general, surgical treatment aims to resection without leaving any tumor at the surgical margin and radical resection with related regional lymph node dissection
(D2 lymphadenectomy) (with or without neoadjuvant or adjuvant chemoradiotherapy). There are various surgical techniques such as total gastrectomy, distal gastrectomy, proximal gastrectomy depending on the stage of the tumor, location, and patient characteristics (2).

Thanks to minimally invasive techniques, laparoscopic gastrectomy (LG) has been developed as an alternative to traditional open gastrectomy (OG) in recent years (3). Recent studies have shown that laparoscopic gastrectomy 
provides a faster recovery with a lower complication rate and less pain than open gastrectomy. Moreover, it has been reported that it is not inferior to open surgery in terms of short-term and long-term survival (3-9). However, the majority of these studies are of Far East origin.

This study aimed to report the short-term results of patients who underwent gastrectomy for gastric cancer at a new regional hospital. We compared the operative characteristics and short-term oncological and postoperative surgical results of open and laparoscopic gastrectomy patients.

\section{MATERIAL AND METHOD}

All procedures applied to the participants in the study were under the 1964 Declaration of Helsinki, and the remedial principles and written informed consent forms were obtained from all patients before surgery. This study was approved by Şehit Prof. Dr. İlhan Varank Training and Research Hospital Ethics Committee (Date: 23.06.2021, Decision No: 2021/172).

Patients who underwent curative surgery diagnosed with gastric cancer between 5 August 2018 - 1 June 2021, in the Şehit Prof. Dr. İlhan Varank Training and Research Hospital were included in the study. Patients operated for benign disease, patients operated for malignancies other than adenocarcinoma, and patients who underwent palliative surgery were excluded from the study. Demographic characteristics of the patients and American Society of Anesthesiologists (ASA) scores, the surgical procedure, duration of surgery, length of hospital stay, time of gas-stool passage, oral intake time, complications, early oncological outcomes, recurrence, and mortality were analyzed retrospectively from a prospectively maintained database.

\section{Patient Selection and Evaluation}

Uppergastrointestinalsystemendoscopywasperformedin all patients preoperatively, and after the histopathological diagnosis was confirmed, thoracoabdominal and pelvis computed tomography (CT) was performed for clinical staging. Antibiotic prophylaxis (2 g cefazolin i.v.) was administered to all patients preoperatively, and additional doses of antibiotics were administered in cases whose operation time exceeded 4 hours. low-molecular-weight heparin (LMWH) was administered 8 to 10 hours before the operation for venous thromboembolism prophylaxis, and medium pressure anti- embolic stockings were worn on the morning of the operation. All patients were evaluated in routine outpatient clinic control on the 10th day after discharge and after the pathology results were obtained (within approximately three weeks). Subsequent follow-ups were performed every 3-6 months in the first year and, every 6-12 months in the following years, depending on the stage of the disease. Postoperative complications were recorded, and the Clavien-Dindo Classification (10) was used for severity. The histopathological classification was made according to WHO 2010 (11). The staging was evaluated by the American Cancer Committee (AJCC) $8^{\text {th }}$ Edition.

\section{Surgical Technique}

All surgeries were performed by the same surgeon (B.G). D2 lymph node dissection was performed routinely in all patients. Open surgery was routinely performed in cases with serosal tumor invasion (T4a), multi-visceral organ resection (T4b), tumor located in the cardia, and a history of the previous laparotomy. The surgeon and the patient made the decision for laparoscopic or open gastrectomy for tumors other than these. The operative time was defined as the time from the first skin incision to the last skin suture. Lymph node dissection was performed according to the Japanese gastric cancer guidelines (12). Roux-en-Y anastomosis (gastrojejunostomy or esophagojejunostomy) was applied in all surgeries for reconstruction, and all anastomoses were performed intracorporeally in laparoscopic surgeries.

\section{Laparoscopic Gastrectomy}

Total Gastrectomy: The patient was placed on the table in the supine position with the legs closed. The operation began with the camera at the patient's left shoulder level and the surgeon on the right of the patient. After the pneumoperitoneum was created with a Veress needle from the supraumbilical area, a 30-degree camera trocar $\left(\right.$ Covidien $^{\text {tx }}$ ) was inserted. The pressure was adjusted to be $10-12 \mathrm{~mm} / \mathrm{Hg}$ using carbon dioxide gas. The operation started in approximately 30 degrees reverse Trendelenburg position. There were three trocars used one $12 \mathrm{~mm}$ from the right midclavicular and umbilicus level, one $5 \mathrm{~mm}$ from the right subcostal area, and one $5 \mathrm{~mm}$ from the left midclavicular-umbilicus level, excluding the left camera port (Figure 1). Two straight needles were tied together with No. 1 silk for liver resection, and gauze was inserted between the needles and placed under the liver. Both needles were removed from the right and left sides of the xiphoid, and the liver was lifted by hanging. The area between the omentum majus and the transverse mesocolon was dissected, and the left gastroepiploic vessels and gastrica breves were ligated together with the regional lymph nodes (no 4) and cut. Then, the right gastroepiploic vessels were cut using a laparoscopic clip (Weck ${ }^{\circledR}$ Hem-O-Lok ${ }^{\circledR}$ Polymer Ligation, Teleflex Medical, Morrisville, USA) at the level of the head of the pancreas with regional lymph nodes (no 6). After dissecting the supra-pyloric region (no 5) and mobilizing the stomach, the duodenum was divided $2 \mathrm{~cm}$ below the pylorus with a linear 
stapler (Endo GIA ${ }^{\mathrm{TM}}$ Articulous Reload with Tri-Staple ${ }^{\mathrm{TM}}$ Technology, Covidien ${ }^{\mathrm{r}}$, USA) (Figure 2A). After the right gastric artery and vein were ligated and cut, the lymph nodes around the hepatoduodenal ligament (no 8) were cleaned. After the celiac artery (no 9) and lymph nodes above the splenic artery (no 11) were dissected, the left gastric artery and vein (no 7) were cut with a similar clip. Right (no 1) and left (no 2) paracardial lymph nodes were dissected, and the esophagus was freed, and then proximal resection was performed with a linear stapler (Figure 2B), and It was removed from the Phinnelstein incision using a wound protector (Alexis ${ }^{\circledast}$ Wound Protector/Retractor, Rancho Santa Margarita, USA). After obtaining the pneumoperitoneum, the reconstruction phase was initiated. The ligament of Trietz was divided approximately $40 \mathrm{~cm}$ distal and a Rouxen-Y esophagojejunostomy anastomosis was performed with a circular stapler (EEA 25, Covidien ${ }^{\circledR}$, USA) or linear stapler (Figure 2C-D). The jejunum stump was closed with a linear stapler (Figure 2E). A side-to-side isoperistaltic jejunojejunostomy anastomosis $50 \mathrm{~cm}$ distal to the anastomosis was performed with a linear stapler, and the stapler opening was closed with a linear stapler again (Figure 2G-F).

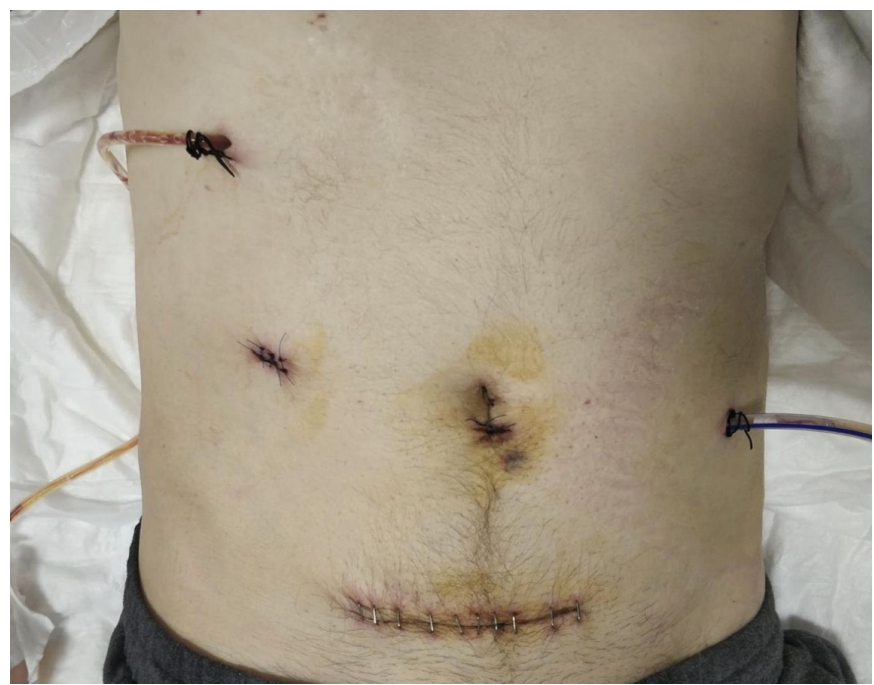

Figure 1. Postoperative trocar sites and Phinnelstein incision

\section{Distal Gastrectomy}

After all procedures were performed as described in total gastrectomy, except the preservation of the gastrica breves (no 4sa), the left paracardial area (no 2) and the distal splenic artery (11d); the stomach was resected approximately $5 \mathrm{~cm}$ proximal to the tumor using a linear stapler. Gastrojejunostomy anastomosis was performed with a linear stapler from the posterior of the stapler line to the greater curvature. The anastomotic opening was closed with a laparoscopic suture (V-Loc ${ }^{\mathrm{TM}}$, Medtronic $^{\mathrm{TM}}$ ) or a linear stapler. Jejunojejunostomy anastomosis was performed as described above.

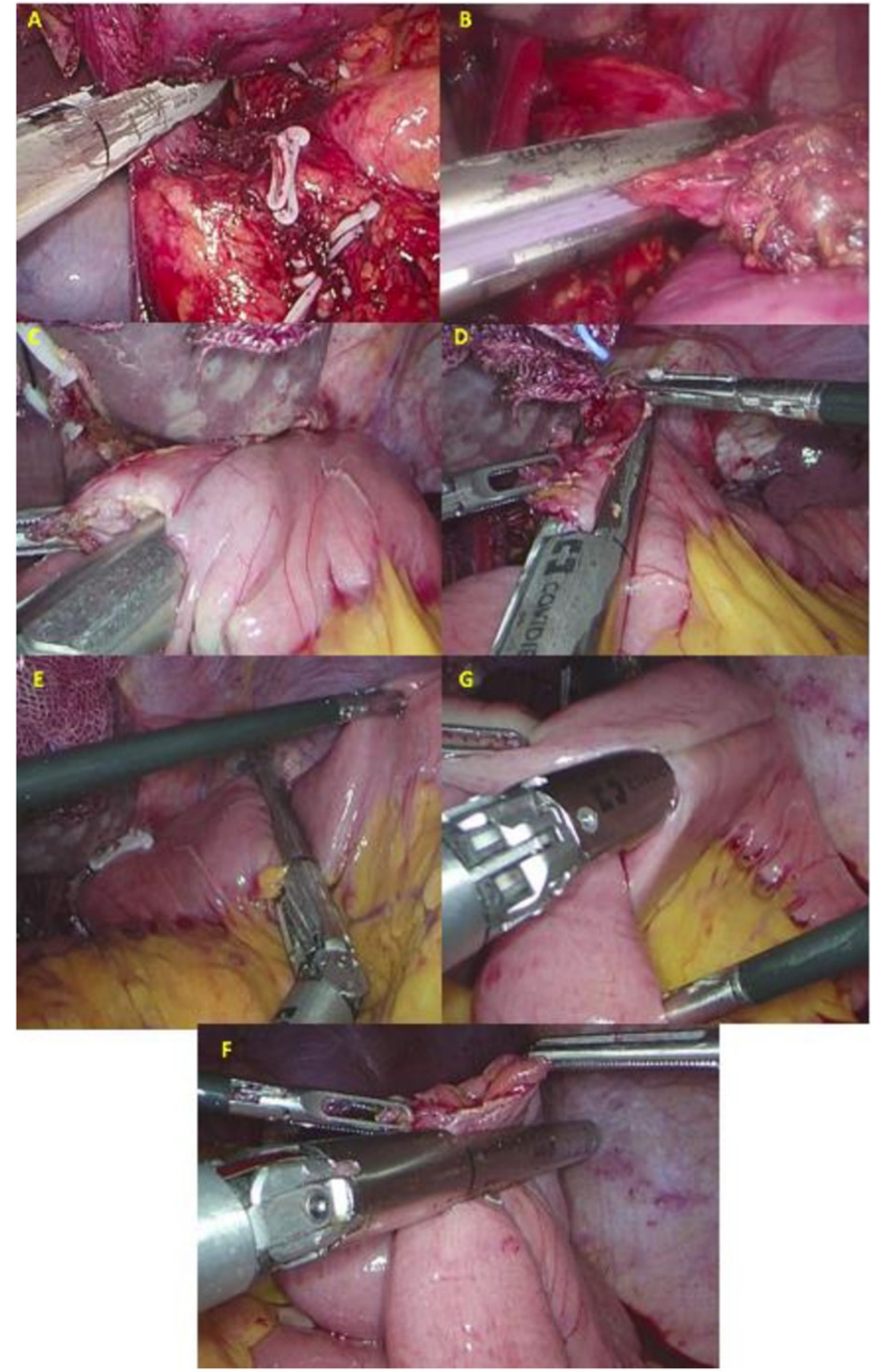

Figure 2. Laparoscopic total gastrectomy stages. A: Transection of the duodenum, B: Transection of the esophagus, C: Esophagojejunostomy anastomosis with linear stapler, D: Closing the staple opening after esophagojejunostomy anastomosis with a similar linear stapler, E: Transection of the jejunum, G: Jejunojejunostomy anastomosis with linear stapler, F: Closing the staple opening after jejunojejunostomy anastomosis with a similar linear stapler

\section{Open gastrectomy}

A laparotomy was performed with a midline incision. Total gastrectomy and distal gastrectomy were performed as described in the laparoscopic procedure.

\section{Proximal Gastrectomy}

Except for the preservation of the right gastropepiploic vessels, right gastric vessels, peripyloric region (no 5, 6), around the hepatoduodenal ligament (no 12) and distal splenic artery (11d), other lymph node stations were excised as described in total gastrectomy. Proximal resection was performed by dividing the esophagus with a linear stapler. Then, the stomach was divided with a linear stapler so that the antrum and pylorus were preserved distally, and the distal resection was completed. The esophagogastric anastomosis was performed with a circular stapler (EEA 25, Covidien ${ }^{\circledR}$, USA). 


\section{Statistical Analysis}

Descriptive statistics were calculated as frequencies and percentages for all variables. Normally distributed continuous variables were presented as mean \pm standard deviation (SD). Categorical data were analyzed using the chi-square test. The Mann-Whitney $U$ test was used for intergroup comparisons of non-normally distributed parameters, and Student's-t independent test was used for intergroup comparisons of normally distributed parameters. The significance level was determined as $\mathrm{p}$ $<0.05$. SPSS for Windows (20.0, SPSS, Chicago, United States of America) was used for all analyses.

\section{RESULTS}

A total of 42 patients underwent gastrectomy. Four patients (neuroendocrine tumor $n=2$, gastrointestinal stromal tumor $\mathrm{n}=2$ ) due to non-adenocarcinoma pathologies, three patients (peptic ulcer bleeding $n=2$, pyloric stenosis $\mathrm{n}=1$ ) due to benign disease, and one patient who underwent palliative surgery were excluded. Then, the remaining 34 patients (male $n=25$, female $\mathrm{n}=9$ ) were included in the study. The mean age was $62.2 \pm 10.5$, and the median follow-up was ten months (2-28 months). The most common tumor localization was the corpus (35.2\%), followed by cardia (26.4\%) and incisura angularis $(17.6 \%)$. The mean operative time was $182.7 \pm 28$ minutes, the estimated blood loss (EBL) was $177.5 \pm 29 \mathrm{~mL}$, and the median hospital stay was five days (4-45 days). In laparoscopic gastrectomy, no conversion to open surgery occurred in any patient.

\section{Comparison of Open and Laparoscopic Gastrectomy Results}

Open gastrectomy (total $\mathrm{n}=18$, distal $=3$, proximal $\mathrm{n}=2$ ) was performed in 23 patients, and laparoscopic gastrectomy (total $n=5$, distal $n=6$ ) was performed in 11 patients. Demographic data were similar between the two groups. When evaluated according to tumor location, the open gastrectomy group (18 patients, 78\%) was mostly located proximal-middle (most common corpus, second cardia), while the laparoscopic gastrectomy group was mostly (8 patients, $73 \%$ ) distal located (most common antrum, second incisura angularis $)(\mathrm{p}=0.01)$. While total gastrectomy was performed in 18 (78\%) patients in the open group, distal gastrectomy was performed in 6 (54.5\%) and total gastrectomy in $5(45.5 \%)$ patients in the laparoscopic group. Additional organ resection was performed in five patients $(22 \%)$ in the open group and two $(18 \%)$ in the laparoscopic group. While the mean operative time was shorter in the open group than in the laparoscopic group (171.5 min and $206 \mathrm{~min}$, respectively, $\mathrm{p}=0.006$ ), the EBLwas less in the laparoscopic group (158.2 $\mathrm{mL}$ vs $186.7 \mathrm{~mL}, \mathrm{p}=0.003$ ) (Table 1).

\begin{tabular}{|c|c|c|c|}
\hline & $\begin{array}{c}\text { Open } \\
(\mathbf{n}=23)\end{array}$ & $\begin{array}{l}\text { Laparoscopic } \\
(n=11)\end{array}$ & $\mathbf{p}$ \\
\hline Age & $63 \pm 12$ & $62 \pm 8$ & 0.782 \\
\hline Sex, n \% & & & 0.665 \\
\hline Female & $6(26)$ & $3(27)$ & \\
\hline Male & $17(74)$ & $8(73)$ & \\
\hline BMI $\left(\mathrm{kg} / \mathrm{m}^{2}\right)$ & $26.7 \pm 3.4$ & $25.4 \pm 2.2$ & 0.183 \\
\hline ASA, n \% & & & 0.441 \\
\hline I & $5(22)$ & $2(18)$ & \\
\hline II & $6(26)$ & $6(54)$ & \\
\hline III & $12(52)$ & $3(28)$ & 0.441 \\
\hline Tumor location, n \% & & & 0.01 \\
\hline Cardia & $8(34.8)$ & $1(9.1)$ & \\
\hline Corpus & $10(43.5)$ & $2(18.1)$ & \\
\hline Lesser curvature & $1(4.3)$ & 0 & \\
\hline Incissura angularis & $1(4.3)$ & $5(45.5)$ & \\
\hline Antrum & $2(8.7)$ & $3(27.2)$ & \\
\hline Other & $1(4.3)$ & 0 & \\
\hline Surgical procedure, n \% & & & 0.283 \\
\hline Total & $18(78.2)$ & $5(45.5)$ & \\
\hline Distal & $3(13.1)$ & $6(54.5)$ & \\
\hline Proximal & $2(8.7)$ & 0 & \\
\hline \multicolumn{2}{|c|}{ Additional organ resection, $\mathrm{n} \%$} & & 0.668 \\
\hline Gall bladder & $1(4.4)$ & $1(9)$ & \\
\hline Transvers colon & $2(8.7)$ & 0 & \\
\hline Sigmoid colon & $1(4.4)$ & $1(9)$ & \\
\hline Liver & $1(4.4)$ & 0 & \\
\hline Operative time ( $\min )$ & $171.5 \pm 17.3$ & $206.4 \pm 32.6$ & 0.006 \\
\hline Estimated blood loss $(\mathrm{mL})$ & $186.7 \pm 28.7$ & $158.2 \pm 20.4$ & 0.003 \\
\hline
\end{tabular}

The histopathological features, mean tumor size and the number of lymph nodes removed were similar between the groups. More metastatic lymph nodes were detected in the open group ( 9.3 vs. 1.7, $\mathrm{p}=0.007$ ). According to TNM Stage, the more advanced disease was detected in the open group ( $\mathrm{p}=0.002)$. The majority of patients in the open group (65\%) were Stage $3 \geq$, the majority of the patients in the laparoscopic group (73\%) were Stage $2 \leq$ (Table 2).

Clavien-Dindo grade $\geq$ III complications were seen in four $(17.4 \%)$ patients in the open group and two (18\%) patients in the laparoscopic group, with a total of six patients $(17.6 \%)(\mathrm{p}=0.96)$. There was an earlier gas passage in the laparoscopic group with a mean difference of one day $(\mathrm{p}=0.002)$. Peritoneal recurrence was detected in two patients $(5.8 \%)$ during their follow-up, while these two patients were in the open group. No operative or disease-related mortality was observed. One patient in the laparoscopic group died due to suicide at the 2 nd month postoperatively, and one in the open group died due to COVID-19 at the 15th postoperative month. The mean follow-up period was longer in the open group than in the laparoscopic group (13.4 months and 7.6 months, respectively, $\mathrm{p}=0.004$ ) (Table 3). 


\begin{tabular}{|c|c|c|c|}
\hline & $\begin{array}{c}\text { Open } \\
(\mathbf{n}=23)\end{array}$ & $\begin{array}{l}\text { Laparoscopic } \\
(\mathbf{n}=11)\end{array}$ & $\mathbf{p}$ \\
\hline Histopathology & & & 0.232 \\
\hline Tubuler adenocarcinoma & 15 & 8 & \\
\hline $\begin{array}{l}\text { Mixt type } \\
\text { adenocarcinoma }\end{array}$ & 5 & 1 & \\
\hline $\begin{array}{l}\text { Mucinous } \\
\text { adenocarcinoma }\end{array}$ & 2 & 1 & \\
\hline $\begin{array}{l}\text { Signet ring cell } \\
\text { adenocarcinoma }\end{array}$ & 1 & 1 & \\
\hline Tumor size (mm) & $45.9 \pm 18.4$ & $43.25 \pm 18.4$ & 0.665 \\
\hline $\begin{array}{l}\text { Number of harvested } \\
\text { lymph node }\end{array}$ & $41.5 \pm 14.1$ & $37.6 \pm 8.3$ & 0.326 \\
\hline $\begin{array}{l}\text { Number of metastatic } \\
\text { lymph node }\end{array}$ & $9.3 \pm 11.9$ & $1.7 \pm 2.8$ & 0.007 \\
\hline Positive surgical margin & 0 & 0 & - \\
\hline pT stage. n \% & & & 0.054 \\
\hline $1 \mathrm{~A}$ & $1(4.4)$ & $1(9)$ & \\
\hline 1B & 0 & 0 & \\
\hline 2 & $2(8.7)$ & $4(36.4)$ & \\
\hline 3 & $15(65)$ & $6(54.5)$ & \\
\hline $4 \mathrm{~A}$ & $4(17.4)$ & 0 & \\
\hline $4 \mathrm{~B}$ & $1(4.4)$ & 0 & \\
\hline pN stage. n \% & & & 0.009 \\
\hline 0 & $4(17.4)$ & $6(54.5)$ & \\
\hline 1 & $3(13)$ & $2(18.2)$ & \\
\hline 2 & $5(21.7)$ & $2(18.2)$ & \\
\hline $3 \mathrm{~A}$ & $8(34.8)$ & $1(9)$ & \\
\hline $3 \mathrm{~B}$ & $3(13)$ & 0 & \\
\hline pTNM stage. n \% & & & 0.002 \\
\hline $1 \mathrm{~A}$ & $1(4.4)$ & $2(18.2)$ & \\
\hline $1 \mathrm{~B}$ & 0 & $2(18.2)$ & \\
\hline $2 \mathrm{~A}$ & $1(4.4)$ & $3(27.2)$ & \\
\hline $2 \mathrm{~B}$ & $6(26)$ & $1(9)$ & \\
\hline $3 \mathrm{~A}$ & $4(17.4)$ & $2(18.2)$ & \\
\hline $3 \mathrm{~B}$ & $8(34.8)$ & $1(9)$ & \\
\hline $3 \mathrm{C}$ & $3(13)$ & 0 & \\
\hline
\end{tabular}

Table 3. Comparison of the groups in terms of postoperative complications and follow-up

\begin{tabular}{|lccc|}
\hline & $\begin{array}{c}\text { Open } \\
(\mathbf{n}=\mathbf{2 3})\end{array}$ & $\begin{array}{c}\text { Laparoscopic } \\
(\mathbf{n}=\mathbf{1 1})\end{array}$ & $\mathbf{p}$ \\
\hline Clavien-Dindo, n \% & & & 0.96 \\
IIIA & $2(8.7)$ & $1(9)$ & \\
$\begin{array}{l}\text { Esophagojejunostomy } \\
\text { anastomotic leak }\end{array}$ & 2 & 1 & \\
$\geq$ IIIB & $2(8.7)$ & $1(9)$ & \\
Duodenal stump leak & 1 & 0 & \\
Bleeding & 1 & 0 & \\
Stapler line opening & 0 & 1 & \\
Gas output (day) & $2.4 \pm 0.8$ & $1.5 \pm 0.5$ & 0.002 \\
Stool output (day) & $2.6 \pm 0.7$ & $2.5 \pm 0.8$ & 0.821 \\
Oral intake time (day) & $1.6 \pm 0.9$ & $1.2 \pm 0.4$ & 0.095 \\
Lenght of hospital stay (DAY) & $7.7 \pm 8.6$ & $8.4 \pm 8.4$ & 0.842 \\
Readmission, n \% & $2(8.7)$ & $1(9)$ & 0.97 \\
Reoperation, $\mathrm{n} \%$ & $2(8.7)$ & $1(9)$ & 0.97 \\
Recurrence, $\mathrm{n} \%$ & $2(8.7)$ & $0(0)$ & 0.162 \\
Mortality, n \% & $1(4.4)$ & $1(9)$ & 0.645 \\
Follow up (month) & $13.4 \pm 7.8$ & $7.6 \pm 3.1$ & 0.004 \\
\hline
\end{tabular}

\section{DISCUSSION}

Laparoscopic gastrectomy provides an advantage with less blood loss in patients undergoing curative surgery with D2 lymph node dissection in gastric cancer. In contrast, open gastrectomy stands out with a shorter operation time. Both methods were similar in terms of the number of harvested lymph nodes and postoperative outcomes such as serious complications, length of hospital stay, and need for reoperation.

Many studies have shown that laparoscopic gastrectomy has advantages over open surgery in terms of early results. These include less complication rate, shorter hospital stay, earlier gas passage, less blood loss, and less postoperative pain. On the other hand, longer operative times were found in laparoscopic gastrectomy $(4,5,13-$ 16). In a multicenter randomized controlled trial (RCT) (KLASS-01) conducted with a total of 1416 patients (laparoscopic $n=705$, open $n=711$ ) in 2016 , it was reported that laparoscopic surgery was advantageous over open surgery in terms of early postoperative results (particularly wound infection) in patients with stage 1 gastric cancer (4). In the long-term results of the same study reported in 2019, similar overall and cancer-specific survival rates were reported, and it was shown to be safe in terms of oncology (3). Another RCT (KLASS-02) with locally advanced gastric cancers showed similar three-year recurrence-free survival rates between laparoscopic and open gastrectomy (laparoscopic $80.3 \%$, open $81.3 \%$ ) (5). Our study had earlier gas passage and less blood loss in the laparoscopic group, similar to the literature. The majority of the open group (78\%) and half of the laparoscopic group (54.5\%) were total gastrectomies. However, the mean operative time was longer in the laparoscopic group (171.5 min versus $206 \mathrm{~min}$ ). Bleeding in laparoscopic surgeries causes dissection plans to disappear, and complications increase. Therefore, at the beginning of the technique, the surgeon aimed to perform a more careful dissection for safe surgery. In addition, the added effort to adhere to oncological principles has been the main reason for the longer operative time in laparoscopic gastrectomy. The lack of conversion to open surgery is the result of this attention.

The laparoscopic group included tumors located more distally. There were two technical and oncological reasons for this. The first was because the surgeon initially selected distally located tumors because it was relatively easier for laparoscopic gastrectomy $(17,18)$. The second was due to concerns about surgical margin safety in proximal tumors. Similarly, patients in the laparoscopic group had an earlier stage. Although RCTs reported that laparoscopic gastrectomy is not inferior to open gastrectomy in terms of both early and long-term 
results in locally advanced gastric cancer, these studies are the results of experienced centers $(5,7)$. Concern for oncologic outcomes led the surgeon to initially select early-stage tumors.

There was no difference between the groups regarding postoperative complications (Clavien-Dindo Grade $\geq \mathrm{III}$ ) and reoperation rates. In the open gastrectomy (distal gastrectomy) group, a patient who used anticoagulants for cardiac valve replacement was re-operated on the first postoperative day due to bleeding. Hemostasis was performed upon detection of bleeding in the form of leakage around the splenic hilus, and the patient was discharged on the eighth postoperative day without any problem. Another patient, on the fifth day after discharge (postoperative day 10), was operated again due to the detection of contrast leakage in the oral contrast CT performed with the complaint of fever and abdominal pain. More than 50\% separation was detected in the gastrojejunostomy staple line and it was converted to total gastrectomy. In this patient and other distal gastrectomy surgeries, the gastrojejunostomy anastomosis was performed (manually or with a stapler) from the posterior of the staple line to the greater curvature, after the proximal stomach was divided with a linear stapler. In this patient, separation was not in the gastrojejunostomy anastomosis but anterior to this anastomosis, in the section divided by the linear stapler. Reinforcement sutures were not routinely placed on the staple line in any case. Therefore, the current situation is likely to have occurred due to a problem with the stapler used. In the laparoscopic gastrectomy group, one patient was reoperated for duodenal stump leakage. This patient underwent simultaneous laparoscopic distal gastrectomy and anterior resection for synchronous gastric and sigmoid colon cancer (19). Esophagojejunostomy anastomotic leakage was detected in three patients (laparoscopic $n=1$, open $n=2$ ) and all were treated conservatively.

In gastric cancer, whose curative treatment is surgical, $\mathrm{R} 0$ resection and adequate lymph node dissection are the most critical parameters that increase the postoperative survival time. In a meta-analysis evaluating the effect of D1 and D2 lymph node dissection on gastric cancer survival, it was reported that there was no difference in survival in early-stage (T1-2) patients, but D2 dissection had significant survival benefit compared to D1 dissection in higher stage (T3-4) patients (13.5\% for D1 and $19.5 \%$ for D2) (20). In our study, an early-stage tumor (T1-2, N0) could not be diagnosed or determined in any patient with preoperative staging. Therefore, standard D2 lymph node dissection was performed in all patients. In the pathological staging results, early-stage tumors were detected in a total of five (14.7\%) patients (laparoscopic $80 \%$, open $20 \%$ ).
At least 15 lymph node dissections are required for the reliable staging of gastric cancer (21). In our study, adequate lymph node dissection was performed in all patients (minimum 20 - maximum 75, Table 2). In addition, the mean number of lymph nodes dissected was similar in both groups (open 41.5, laparoscopic 37.6, $\mathrm{p}=0.32$ ). Both the absence of positive surgical margins and adequate lymphadenectomy are indicators of the oncological reliability of this study. Two patients with total recurrence were also in the open gastrectomy group. The main reason for this situation is that patients who underwent open gastrectomy have more advanced disease and more extended follow-up periods.

\section{Limitations and Strenghts of the Study}

This study has some limitations. First of all, this is a retrospective study conducted in a single center. Second, there are relatively few cases. Third, the decision for laparoscopic or open gastrectomy was made primarily by the surgeon, and earlier stage tumors were selected. This causes selection bias. Finally, we did not use endoscopic ultrasonography (EUS) for preoperative staging. The main reason for this is the absence of an EUS device and an experienced healthcare professional. On the other hand, the completeness of the data and the absence of loss in follow-up are the strengths of the study.

\section{CONCLUSION}

In this study, the experiences of a single surgeon who performed gastrectomy for gastric cancer at a new regional hospital were presented. The short-term results of patients who underwent laparoscopic and open gastrectomy were compared. Especially in laparoscopic gastrectomy, until sufficient experience is reached, choosing earlier stage and distally located tumors may be a safe option with postoperative results similar to open gastrectomy.

\section{ETHICAL DECLARATIONS}

Ethics Committee Approval: This study was approved by Şehit Prof. Dr. İlhan Varank Training and Research Hospital Ethics Committee (Date: 23.06.2021, Decision No: 2021 / 172).

Informed Consent: All patients signed the free and informed consent form.

Referee Evaluation Process: Externally peer-reviewed.

Conflict of Interest Statement: The authors have no conflicts of interest to declare.

Financial Disclosure: The authors declared that this study had received no financial support.

Author Contributions: All of the authors declare that they have all participated in the design, execution, and analysis of the paper and approved the final version. 


\section{REFERENCES}

1. Sung H, Ferlay J, Siegel RL, et al. Global Cancer Statistics 2020: GLOBOCAN estimates of incidence and mortality worldwide for 36 cancers in 185 countries. CA Cancer J Clin 2021; 71: 209-49.

2. Smyth EC, Nilsson M, Grabsch HI, van Grieken NC, Lordick F. Gastric cancer. The Lancet. 2020; 396: 635-48.

3. Kim HH, Han SU, Kim MC, et al. Effect of laparoscopic distal gastrectomy vs open distal gastrectomy on long-term survival among patients with stage I gastric cancer: the KLASS-01 randomized clinical trial. JAMA Oncol 2019; 5: 506-13.

4. Kim W, Kim HH, Han SU, et al. Decreased morbidity of laparoscopic distal gastrectomy compared with open distal gastrectomy for stage 1 gastric cancer: short-term outcomes from a multicenter randomized controlled trial (KLASS-01). Ann Surg 2016; 263: 28-35.

5. Hyung WJ, Yang HK, Park YK, et al. Long-term outcomes of laparoscopic distal gastrectomy for locally advanced gastric cancer: the KLASS-02-RCT randomized clinical trial. JCO 2020; 38: 3304-13.

6. van der Wielen N, Straatman J, Daams F, et al. Open versus minimally invasive total gastrectomy after neoadjuvant chemotherapy: results of a European randomized trial. Gastric Cancer 2021; 24: 258-71.

7. Lee H-J, Hyung WJ, Yang H-K, et al. Short-term outcomes of a multicenter randomized controlled trial comparing laparoscopic distal gastrectomy with D2 lymphadenectomy to open distal gastrectomy for locally advanced gastric cancer (KLASS-02RCT). Ann Surg 2019; 270: 983-91.

8. Yu J, Huang C, Sun Y, et al. Effect of laparoscopic vs open distal gastrectomy on 3-year disease-free survival in patients with locally advanced gastric cancer. JAMA 2019; 321: 1983-92.

9. Liu F, Huang C, Xu Z, et al. Morbidity and mortality of laparoscopic vs open total gastrectomy for clinical stage i gastric cancer: the CLASS02 multicenter randomized clinical trial. JAMA Oncol 2020; 6: 1590-97.

10.Dindo D, Demartines N, Clavien PA. Classification of surgical complications. Ann Surg 2004; 240: 205-13.

11.Berlth F, Bollschweiler E, Drebber U, Hoelscher AH, Moenig S. Pathohistological classification systems in gastric cancer: Diagnostic relevance and prognostic value. World J Gastroenterol 2014; 20: 5679-84.

12. Japanese gastric cancer treatment guidelines 2018 (5th edition). Gastric Cancer 2021; 24: 1-21.

13.Zeng F, Chen L, Liao M, et al. Laparoscopic versus open gastrectomy for gastric cancer. World J Surg Oncol 2020; 18: 20.

14.Zhang W, Huang Z, Zhang J, Che X. Long-term and short-term outcomes after laparoscopic versus open surgery for advanced gastric cancer: An updated meta-analysis. J Minim Access Surg. 2021 May 6. doi: 10.4103/jmas.JMAS_219_20. Epub ahead of print. PMID: 34045399.

15. Ammori BJ, Asmer H, Al-Najjar H, et al. Laparoscopic versus open D2 gastrectomy for gastric cancer: a case-matched comparative study. J Laparoendosc Adv Surg Tech A 2020; 30: 777-82.

16. Li B, Yu-Hong Wong I, Siu-Yin Chan F, et al. Comparison of laparoscopic versus open gastrectomy for gastric cancer. Surg Oncol 2020; 35: 14-21.

17.Jung DH, Son S-Y, Park YS, et al. The learning curve associated with laparoscopic total gastrectomy. Gastric Cancer 2016; 19: 264-72.

18. Chi F, Lan Y, Zhou S, Yang L, Chen M, Bi T. Learning curve of totally laparoscopic distal gastrectomy for gastric cancer: a single teaching hospital study. Wideochir Inne Tech Maloinwazyjne. 2018; 13: 442-7.

19. Goksoy B. Simultaneous totally laparoscopic distal gastrectomy and anterior resection for synchronous gastric and colon cancer. Cureus 2021; 13: e15692.
20.Seevaratnam R, Bocicariu A, Cardoso R, et al. A meta-analysis of D1 versus D2 lymph node dissection. Gastric Cancer 2012; 15 : 60-9.

21. Naffouje SA, Salti GI. Extensive lymph node dissection improves survival among american patients with gastric adenocarcinoma treated surgically: analysis of the national cancer database. J Gastric Cancer 2017; 17: 319-30. 